\title{
Decadal land-use/land-cover and land surface temperature change in Dubai and implications on the urban heat island effect: A preliminary assessment
}

\author{
Abdulhakim M. Abdi 1,2,* \\ ${ }^{1}$ Institute for Geoinformatics, Universität Münster, Weseler Straße 253, Münster 48151, Germany \\ ${ }^{2}$ Institute of Statistics and Information Management, Universidade Nova de Lisboa, Lisbon 1070-312, \\ Portugal \\ * Current Address: Department of Physical Geography and Ecosystem Science, Lund University, \\ Sölvegatan 12, Lund 223 62, Sweden; E-Mail: hakim.abdi@nateko.lu.se
}

\begin{abstract}
The emirate of Dubai is the most populous and most developed of the seven emirates that comprise the United Arab Emirates (UAE). By the end of the $20^{\text {th }}$ century, the emirate had shifted its economy from being primarily petroleum-based to a focus on tourism and financial services. The emirate's capital, also named Dubai, has been growing at a rapid pace; the population in 1999 was 862,000 inhabitants, and increased in ten years to 1.8 million. In this letter, I evaluate the extent of land cover and land surface temperature change between 1999 and 2009. Landsat ETM+ satellite images from the month of September 1999 and 2009 were used in this study. Both images were classified using spectral information divergence to measure the discrepancy of probabilistic behaviors between spectral signatures of different surfaces in the study area. Changes in land cover between 1999 and 2009 were quantified using post-classification analysis in a geographic information system. The results have shown a $76.11 \%$ change in land cover and a $1.75^{\circ} \mathrm{C}$ average increase in land surface temperature over the 10-year study period. The composition of land cover features significantly influence the magnitude of land surface temperature and the percent cover of stabilized land and impervious surfaces have had the most substantial affect. In contrast, the percentage of vegetation cover is the most essential driver that alleviates land surface and ambient temperature. Keeping the cooling effects of urban greenery in perspective, I suggest that their proper management can directly mitigate the urban heat island effect in Dubai.
\end{abstract}

Keywords: Dubai; Land-cover; Land-use; Land surface temperature; Landsat; ETM+; Persian Gulf; UAE; Urban heat island.

\section{Introduction}

The United Arab Emirates (UAE) is a federation of seven emirates located on the southeastern shore of the Persian Gulf (Figure 1). The emirate of Dubai is the most populous and most developed of 
the seven emirates that comprise the country. By the end of the $20^{\text {th }}$ century, the emirate shifted its economy from being primarily petroleum-based to a focus on tourism and financial services. The emirate's capital, also named Dubai, has been growing at a rapid pace; the population in 1999 was 862,000 inhabitants, which more than doubled in ten years to 1.8 million by 2009 [1]. This growth has been accompanied by ambitious land reclamation projects that included artificial islands such as the "Palm Jebel Ali", "Palm Jumeirah", "Palm Deira" and "The World". These offshore features, as well as the altered landscape of the area, are easily discernable using medium resolution satellite imagery.

Earth observation data has been used extensively in recent years to monitor changes at a global [2], regional [3] and local levels [4]. In the UAE, remote sensing studies have been primarily focused on land management and vegetation mapping $[5,6,7]$, coastal sensitivity mapping $[8,9]$, and urban land use and land cover [10,11].

The objectives of this study are: (1) to quantify changes in land cover and assess the effects of urbanization in the Dubai metropolitan area; (2) to derive land surface temperature change in the metropolitan area and analyze its spatial variations; and (3) to investigate the relationship between land surface temperature and land cover.

\section{Methods}

\subsection{Study Area}

The study area is the Dubai Metropolitan Area (Figure 1), which includes the sections of Jumeirah, Bur Dubai, Deira and Jebel Ali. The southern border of the study area is the Dubai Outer Road. The westernmost extent is the Palm Jebel Ali and the easternmost extent is the Palm Deira (currently under construction).

\subsection{Data}

The Enhanced Thematic Mapper Plus (ETM+) sensor on board the Landsat 7 satellite was used to provide the required imagery. Scenes from the month of September for the years 1999 and 2009 were downloaded from the USGS Global Visualization Viewer (GLOVIS). The imagery is standard level one terrain corrected (L1T) and has systematic radiometric and geometric correction through the incorporation of ground control points and a digital elevation model. I chose ETM+ because it offers high temporal and medium spatial resolutions for no cost. Landsat imagery has been extensively used in recent years and is proven adequate for this type of study $[12,13]$. However, the ETM+ Scan Line Corrector (SLC) has been inoperational since May 2003; this malfunction has caused the imagery to possess a number of data gaps in the form of diagonal striations (Figure 5A, supplemental material). Most of the study area lies in the unaffected zone, and the part that is affected is comprised of relatively narrow bands that were $150 \mathrm{~m}$ wide at their thickest and $60 \mathrm{~m}$ wide at their narrowest. Therefore, prior to classification, the scene had to be preprocessed in order to fill the areas that were devoid of data. I used cubic spline interpolation in MATLAB to fill the regions that had no data. This method was preferred over linear interpolation because the interpolation error was low even when using low degree polynomials for the spline. MATLAB performs a one-dimensional interpolation by 
fitting the supplied data with polynomial functions between data points and evaluating the appropriate function at the desired interpolation points. This technique proved successful, as the resultant scene was free of data gaps (Figure 5B, supplemental material). I then corrected the images for atmospheric effects using the QUick Atmospheric Correction method (QUAC), which determines parameters directly from information present in the scene through the utilization of observed pixel spectra. QUAC is an in-scene approach to atmospheric correction and allows the collection of fairly accurate reflectance spectra even when the sensor does not possess appropriate radiometric calibration or when certain parameters such as the solar intensity are unknown [14].

Figure 1. Overview of the United Arab Emirates and the city of Dubai. The location of the Dubai International Airport weather station is highlighted and will be discussed later in the text.

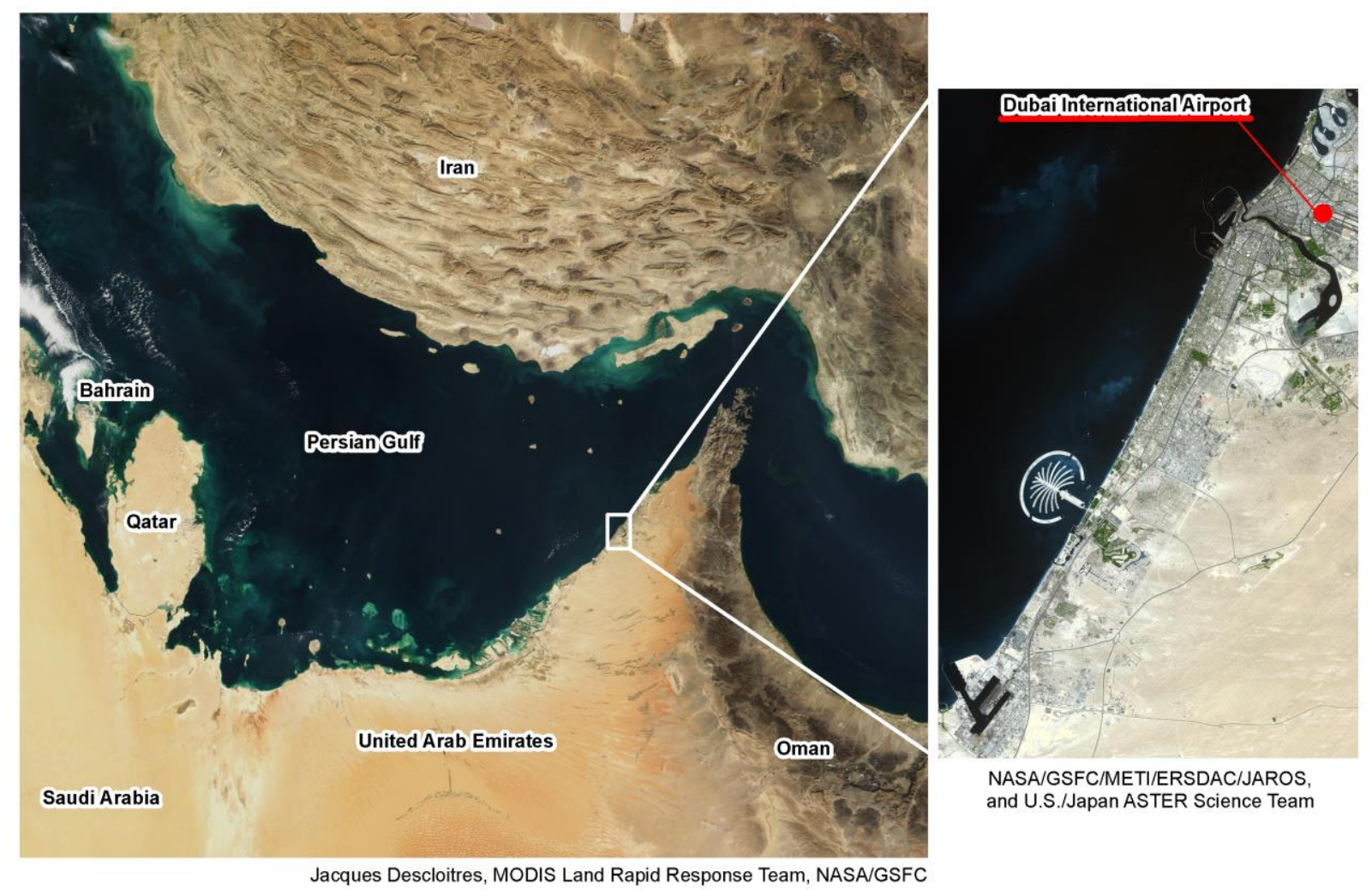

\subsection{Land Cover Classification}

Images were classified in ENVI using spectral information divergence (SID) [15], a stochastic spectral similarity method that employs a quantification of divergence that correspond pixels to particular reference spectra. The pixels are likely to be analogous if the divergence value is low. A threshold level was specified and pixels having measurements greater than that level are excluded from the classification. Representative training data were collected for each class using regions of interest (ROIs) and endmember reference spectra were calculated using the average spectra values in each class. SID presents a different perspective of the similarity between two spectral signatures through the 
use of the concept of divergence [16] to calculate the inconsistency of probabilistic behaviors of the spectral information provided by each signature. I used the enhanced vegetation index, (EVI) [17] to discriminate green areas from the rest of the urban landscape. EVI augments the vegetation signal, reduces soil background noise and removes any remaining effects from the atmosphere [17].

Table 1. Description of land cover classes selected for the study.

\begin{tabular}{c|l}
\hline Class & \multicolumn{1}{c}{ Description } \\
\hline Bare Ground & $\begin{array}{l}\text { Exposed soil, rock or consolidated hard surfaces resulting from } \\
\text { sand stabilization activities. These surfaces are not covered by } \\
\text { vegetation or sand. }\end{array}$ \\
\hline High Intensity Urban & $\begin{array}{l}\text { Highly developed areas where people reside or work in high } \\
\text { numbers e.g. apartment complexes and commercial/industrial } \\
\text { buildings. Impervious surfaces account for } 80 \text { to } 100 \text { percent of } \\
\text { the total cover. }\end{array}$ \\
\hline Low Intensity Urban & $\begin{array}{l}\text { Areas with a mixture of constructed space and vegetation. } \\
\text { Impervious surfaces account for 50-79 percent of the total cover. } \\
\text { These areas most commonly include family villas and } \\
\text { neighborhoods with ample greenery such as parks and roadside } \\
\text { vegetation. }\end{array}$ \\
\hline Loose or Shifting Sand & $\begin{array}{l}\text { Areas of natural desert, covered by sand particles that may be } \\
\text { moved by regularly occurring winds and form clear directional } \\
\text { patterns. }\end{array}$ \\
\hline Vegetation & Green urban areas e.g. parks and gardens. EVI value >0.0 \\
\hline
\end{tabular}

\subsection{Land Surface Temperature}

The urban climate of Dubai is affected by changes in land use, vegetation cover, and the expansion of built-up areas, hence, land surface temperature (LST) was included in the analysis as an indicator of urban expansion, and to detect urban heat island (UHI) effects. Radiation released by terrestrial surfaces is recorded by LST; hence, it could be influenced by the spatial arrangement of an urban landscape.

In order to measure change in LST from 1999 and 2009, radiant temperatures were derived from ETM+ thermal infrared data (band 6) following steps outlined in the Landsat 7 Science Data Users Handbook [18], emissivity was calculated using methodology described in Sobrino et. al. [19], and surface temperature was derived using the methodology in Weng et. al. [13]. Mean LST estimate per land cover class was calculated using polygon summary statistics in a geographic information system (GIS) by superimposing LST data (in raster format) with the corresponding land cover data (in vector format). 
Since there were no offshore developments in 1999, I created a land/water mask using the 2009 image to extract areas of offshore development and then superimposed that mask on the earlier image to quantify areas of water in 1999 that were converted to other land cover classes in 2009. I then used an error matrix to assess the accuracy of the land cover maps by comparing the classification results with reference data. The 1999 land cover map was validated using 500 random reference samples (100 per land cover class) collected in October 1999, and reference data for the 2009 land cover map were collected using 500 random samples (100 per land cover class) collected from high resolution Google Earth imagery from September 2009 (Figure 4, supplemental material). Overall accuracy and Kappa coefficient [20] were used to measure the performance of the classification. Kappa is a measure of agreement and accuracy with values greater than 0.80 represent strong agreement between the classified image and the reference data [21].

\section{Results and Discussion}

The overall accuracy of the land cover maps for 1999 and 2009 were $91.86 \%$ and 84.04\%, respectively (Table 2). Kappa values for 1999 and 2009 were 0.88 and 0.81, respectively. It is evident from these data that the reasonably high accuracy of the classification is appropriate for the stated purposes of this study. Table 3 displays the land cover change matrix from 1999 to 2009, and it is clear that there has been a substantial change $(76.11 \%)$ in the land cover of the total area.

The High and Low Intensity Urban areas exhibited the largest percent increase $(354.47 \%$ and $120.35 \%$, respectively) followed by Vegetation (94.36\%). This urban sprawl is directional towards the east and southwest. The eastward trend could reflect the creation of suburban commuter districts caused by the two-fold increase in population during the 10-year period of the study. The southwest trend could be caused by commercial expansion of the Jebel Ali Industrial Zone.

Table 2. User's and Producer's accuracies and Kappa coefficients for the classification results.

\begin{tabular}{|c|c|c|c|c|}
\hline \multirow{3}{*}{ Classes } & \multicolumn{2}{|c|}{1999 Classification } & \multicolumn{2}{|c|}{2009 Classification } \\
\hline & \multicolumn{2}{|c|}{ Accuracy $(\%)$} & \multicolumn{2}{|c|}{ Accuracy $(\%)$} \\
\hline & Prod. Acc. & User Acc. & Prod. Acc. & User Acc. \\
\hline High Intensity Urban & 82.98 & 86.02 & 84.65 & 68.52 \\
\hline Low Intensity Urban & 89.81 & 72.66 & 87.33 & 94.03 \\
\hline Vegetation & 99.27 & 87.82 & 97.12 & 99.80 \\
\hline Bare Ground & 69.24 & 98.99 & 65.47 & 84.48 \\
\hline Loose or Shifting Sand & 99.76 & 84.21 & 92.40 & 80.00 \\
\hline Overall Accuracy (\%) & \multicolumn{2}{|c|}{91.86} & \multicolumn{2}{|c|}{84.04} \\
\hline Kappa Coefficient & \multicolumn{2}{|c|}{0.88} & \multicolumn{2}{|c|}{0.81} \\
\hline
\end{tabular}


Table 3. Results of the change detection analysis $\left(\mathrm{km}^{2}\right)$. The water mask provided useful information about the area of water that was displaced by different land cover classes.

Final Land Cover (2009)

\begin{tabular}{|c|c|c|c|c|c|c|c|}
\hline & $\begin{array}{l}\text { High } \\
\text { Intensity } \\
\text { Urban }\end{array}$ & $\begin{array}{l}\text { Low } \\
\text { Intensity } \\
\text { Urban }\end{array}$ & Vegetation & $\begin{array}{l}\text { Loose or } \\
\text { Shifting } \\
\text { Sand }\end{array}$ & $\begin{array}{l}\text { Bare } \\
\text { Ground }\end{array}$ & Water & $\begin{array}{c}1999 \\
\text { Total } \\
\left(\mathrm{km}^{2}\right) \\
\end{array}$ \\
\hline $\begin{array}{l}\text { High Intensity } \\
\text { Urban }\end{array}$ & 22.03 & 4.63 & 0.31 & 0.00 & 0.00 & 0.00 & 26.97 \\
\hline $\begin{array}{l}\text { Low Intensity } \\
\text { Urban }\end{array}$ & 54.59 & 167.33 & 7.98 & 0.00 & 0.03 & 0.00 & 229.93 \\
\hline Vegetation & 2.23 & 2.01 & 10.47 & 0.00 & 0.01 & 0.00 & 14.72 \\
\hline $\begin{array}{l}\text { Loose or Shifting } \\
\text { Sand }\end{array}$ & 10.82 & 164.41 & 6.32 & 485.98 & 454.56 & 0.00 & 1122.09 \\
\hline Bare Ground & 20.53 & 131.62 & 3.49 & 1.51 & 224.76 & 0.00 & 381.91 \\
\hline Water & 12.37 & 36.65 & 0.04 & 0.45 & 17.72 & 0.00 & 67.23 \\
\hline 2009 Total $\left(\mathrm{km}^{2}\right)$ & 122.57 & 506.65 & 28.61 & 487.94 & 697.08 & 0.00 & 1842.85 \\
\hline Change $\left(\mathrm{km}^{2}\right)$ & 95.60 & 276.72 & 13.89 & -634.15 & 315.17 & -67.23 & 1402.76 \\
\hline Change (\%) & 354.47 & 120.35 & 94.36 & -56.52 & 82.52 & -100.00 & \\
\hline
\end{tabular}

Table 4. Mean land surface temperature in degrees Celsius by land cover type.

\begin{tabular}{lcc|cc|c}
\hline \multirow{2}{*}{ Class } & \multicolumn{2}{c|}{1999} & \multicolumn{2}{c|}{2009} & \multirow{2}{*}{$\Delta \mathrm{T}$} \\
\cline { 2 - 5 } & Mean & $\begin{array}{c}\text { Standard } \\
\text { Deviation }\end{array}$ & Mean & $\begin{array}{c}\text { Standard } \\
\text { Deviation }\end{array}$ & \\
\hline Bare Ground & 51.35 & 6.13 & 55.26 & 7.47 & +3.91 \\
High Intensity Urban & 48.84 & 2.40 & 51.18 & 3.36 & +2.34 \\
Low Intensity Urban & 45.10 & 3.61 & 46.89 & 3.74 & +1.79 \\
Loose or Shifting Sand & 47.83 & 0.52 & 48.09 & 0.58 & +0.26 \\
Vegetation & 33.54 & 1.04 & 33.98 & 1.74 & +0.44 \\
\hline
\end{tabular}


Table 4 shows the mean values of LST by land cover type in 1999 and 2009. The high temperature exhibited by the Bare Ground land cover class in $2009\left(55.26^{\circ} \mathrm{C}\right)$ could be attributed to the application of mechanical or chemical stabilization methods such as leveling with heavy machinery and the use of lime mixtures on areas of Loose and Shifting Sand that were coverted in preparation for development. This lowers the albedo and increases absorption of incident solar energy.

It is clear that Low Intensity Urban areas are cooler than High Intensity ones due to the greater prevalence of urban vegetation. This cooling effect is related to the $94.36 \%$ increase in urban vegetation between 1999 and 2009. In contrast, there has been a $2.06^{\circ} \mathrm{C}$ increase in mean urban LST, which is explained by the increase in non-porous, and non-evapotranspirative materials that constitute the High and Low Intensity Urban landscapes [22]. Note that this increase in urban LST is higher than mean increase in all land cover types $\left(1.75^{\circ} \mathrm{C}\right)$ indicating that the urban landscape drives climatic conditions within its vicinity.

Figure 2. Land cover and land surface temperature maps of the Dubai Metropolitan Area for 1999 and 2009.

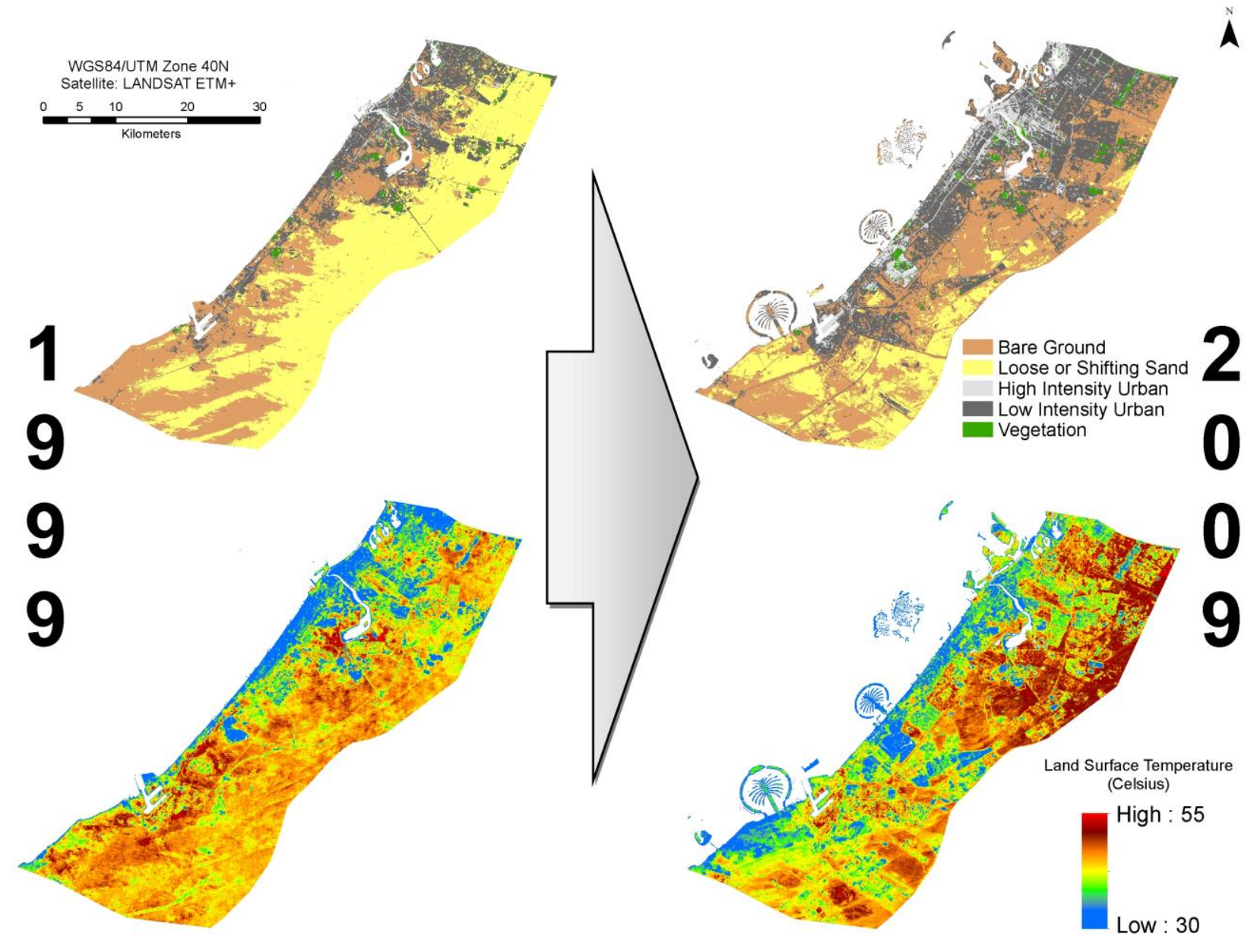


Figure 2 illustrates the visual results of the land cover classification as well as corresponding LST estimation. Note that there is an obvious increase in high-LST Bare Ground and High Intensity Urban areas in 2009. Figure 3 shows the ambient temperature recorded by the weather station in Dubai International Airport (Figure 1). There was a $1{ }^{\circ} \mathrm{C}$ increase in the mean ambient temperature between 1999 and 2009, which could relate to the $2^{\circ} \mathrm{C}$ increase in mean urban LST. The intensified use of air conditioning during the summer months [23] should also be considered a factor that increases the ambient temperature. This increase is comparable with Saaroni and Ziv [24] who reported that UHI effect contributed an average of $0.64^{\circ} \mathrm{C}(10 \mathrm{yr})^{-1}$ surge in summer temperatures in an arid city that experienced urbanization and increase in population (albeit at a slower pace than Dubai). According to Comrie [25] UHI effect caused an increase of $2^{\circ} \mathrm{C}$ in Tucson, Arizona over 30 years, which is within the decadal increase reported by Saaroni and Ziv. In comparison, Dubai's $1^{\circ} \mathrm{C}$ increase in temperature between 1999 and 2009 (Figure 3) is 35\% higher than those studies because of the higher rates of population increase and urban expansion.

Figure 3. Average daily temperatures in degrees Celsius recorded by the Dubai International Airport weather station (OMDB) located at $25^{\circ} 15^{\prime} 35.91^{\prime \prime} \mathrm{N}$ and $55^{\circ} 22^{\prime} 18.36^{\prime \prime} \mathrm{E}$ (see Fig 1). Mean monthly air temperature for September 2009 was $1^{\circ} \mathrm{C}$ higher than September 1999.

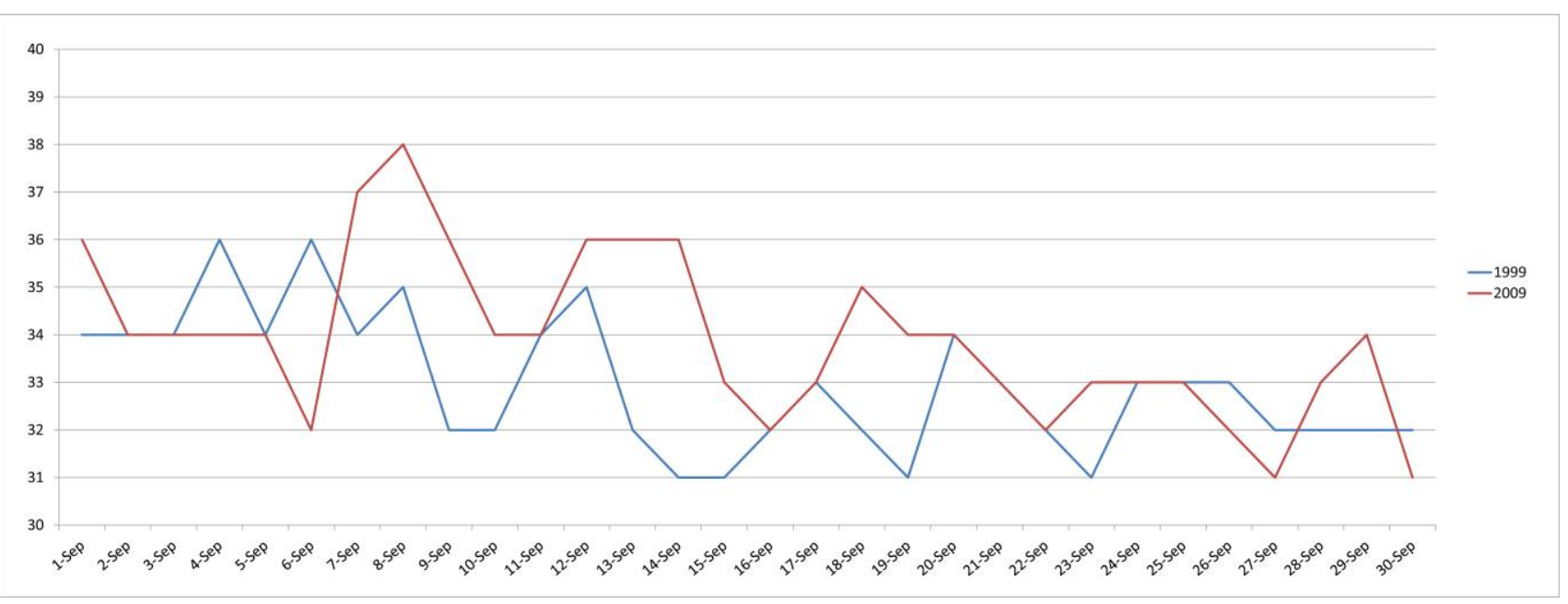

The results presented here are consistent with previous studies [12, 13, 22, 24] that different types of land cover significantly influence LST and that increase in urban vegetation cover greatly reduces LST and by extension UHI. In this regard, LST can provide important acumens for urban design and management, wherein the local climatological influence of UHI can be controlled by balancing the comparative quantities of different land cover features (particularly vegetation) and improving their spatial arrangements.

\section{Conclusions}

In this letter, I conducted a preliminary characterization of the extent of land cover and surface temperature change in Dubai between 1999 and 2009 using Landsat ETM+ imagery. The accuracy of 
the land cover classification was $91.86 \%$ and $84.04 \%$ for the 1999 and 2009 land cover maps, respectively. The applied methodology was successful in analyzing the spatial dynamics of land cover change and associated changes in daytime urban heat island effect. The study has implications for urban design and spatial planning in other rapidly expanding arid cities in the region.

The results suggest that the composition of land cover features significantly influence the magnitude of land surface temperature, and that the percent cover of stabilized land and impervious surfaces have the most substantial affect. In contrast, the percent of vegetation is the most essential driver of alleviating land surface temperature. Keeping the cooling effects of urban greenery in perspective, their proper management can directly mitigate the urban heat island effect in Dubai.

Change detection techniques in remote sensing are a viable tool in monitoring rapidly growing cities such as Dubai, and the 2008 Landsat open data policy from the United States Geological Survey [26] begun a new age for using time-series imagery for that purpose. The free availability of three decades of Landsat data provides invaluable insight into the dynamics of urbanization and its impacts on natural resources. On a broader scale, the world's urban population is projected to reach 9.3 billion by 2050 [27], making local climatic effects caused by urban environments a significant contributor to global climate change.

\section{Acknowledgments}

This work is a part of a graduate project conducted by the author and supported by the European Commission, Erasmus Mundus Program, Master of Science in Geospatial Technologies, Framework Partnership Agreement 2007-0064/001 FRAME MUNB123.

\section{References}

1. Dubai Statistics Center. Population by Sex - Emirate of Dubai. Available online: http://www.dsc.gov.ae/Reports/DSC_SYB_2009_01_01.pdf (retrieved on December 14, 2009)

2. Friedl, M.A.; McIver, D.K.; Hodges, J.C.F.; Zhang, X.Y.; Muchoney, D.; Strahler, A.H.; Woodcock, C.E.; Gopal, S.; Schneider, A.; Cooper, A.; Baccini, A.; Gao, F.; Schaaf, C. Global land cover mapping from MODIS: algorithms and early results. Remote Sens. Environ. 2002, 83, 287-302.

3. Kilic, S.; Evrendilek, F.; Berberoglu, S.; Demirkesen, A. Environmental Monitoring of LandUse and Land-Cover Changes in a Mediterranean Region of Turkey. Environ. Monit. Assess. 2006, 114, 157-168.

4. Shalaby, A.; Tateishi, R. Remote sensing and GIS for mapping and monitoring land cover and land-use changes in the Northwestern coastal zone of Egypt. J. App. Geo. 2007, 27, 28-41.

5. Issa, S. An integrated geo-database for land management and greening assessment of an arid island at the fringes of Abu Dhabi city. Canadian Journal of Pure and Applied Sciences 2008, 2, 431-440.

6. Starbuck, M.J.; Tamayo, J. Monitoring vegetation change in Abu Dhabi emirate from 1996 to 2000 and 2004 using landsat satellite imagery. Arab Gulf Journal of Scientific Research 2007, $25,71-80$.

7. Alhammadi, M.S.; Glenn, E.P. Detecting date palm trees health and vegetation greenness change on the eastern coast of the United Arab Emirates using SAVI. Int. J. Remote Sens. 2008, 29, 1745-1765. 
8. Jensen, J.R.; Narumalani, S.; Weatherbee, O.; Murday, M.; Sexton, W.J.; Green, C.J. Coastal environmental sensitivity mapping for oil spills in the United Arab Emirates using remote sensing and GIS technology. Geocart. Int. 1993, 8, 5-13.

9. Yagoub, M.; Kolan, G. Monitoring coastal zone land use and land cover changes of Abu Dhabi using remote sensing. J. Indian Soc. Remote Sens. 2006, 34, 57-68.

10. Yagoub, M.M. Monitoring of urban growth of a desert city through remote sensing: Al-Ain, UAE, between 1976 and 2000. Int. J. Remote Sens. 2004, 25, 1063-1076.

11. Abdi, A.M.; Nandipati, A. Abu Dhabi Island: Analysis of Development and Vegetation Change Using Remote Sensing (1972-2000). In Advances in Earth Observation of Global Change; Chuvieco, E.; Li, J.; Yang, X., Eds.; Springer Netherlands: 2010; pp. 43-53.

12. $\mathrm{Hu}, \mathrm{Y}$.; Jia, G. Influence of land use change on urban heat island derived from multi-sensor data. Int. J. Climatol. 2010, 30, 1382-1395.

13. Weng, Q.; Lu, D.; Schubring, J. Estimation of land surface temperature-vegetation abundance relationship for urban heat island studies. Remote Sens. Environ. 2004, 89, 467-483.

14. Bernstein, L.S.; Adler-Golden, S.M.; Sundberg, R.L.; Levine, R.Y.; Perkins, T.C.; Berk, A.; Ratkowski, A.J.; Felde, G.; Hoke, M.L. Validation of the QUick atmospheric correction (QUAC) algorithm for VNIR-SWIR multi- and hyperspectral imagery. In Algorithms and Technologies for Multispectral, Hyperspectral, and Ultraspectral Imagery XI. Orlando, FL, USA, 2005; Shen, S. S.; Lewis, P. E., Eds. SPIE: Orlando, FL, USA, 2005; pp. 668-678.

15. Du, Y.; Chang, C.-I.; Ren, H.; Chang, C.-C.; Jensen, J.O.; D'Amico, F.M. New hyperspectral discrimination measure for spectral characterization. Opt. Eng. 2004, 43, 1777-1786.

16. Chang, C.I. An information-theoretic approach to spectral variability, similarity, and discrimination for hyperspectral image analysis. IEEE Trans. Info. Theory 2000, 46, 19271932.

17. Huete, A.; Didan, K.; Miura, T.; Rodriguez, E.P.; Gao, X.; Ferreira, L.G. Overview of the radiometric and biophysical performance of the MODIS vegetation indices. Remote Sens. Environ. 2002, 83, 195-213.

18. Landsat 7 Science Data Users Handbook. Available online: http://landsathandbook.gsfc.nasa.gov/ (retrieved on January 7, 2010)

19. Sobrino, J.A.; Jiménez-Muñoz, J.C.; Paolini, L. Land surface temperature retrieval from LANDSAT TM 5. Remote Sens. Environ. 2004, 90, 434-440.

20. Cohen, J. A Coefficient of Agreement for Nominal Scales. Edu. Psychol. Meas. 1960, 20, 3746.

21. Congalton, R.G.; Green, K. Assessing the Accuracy of Remotely Sensed Data; CRC Press: Boca Raton, Florida, 2009; pp.105-110.

22. Lo, C.P.; Quattrochi, D.A.; Luvall, J.C. Application of high-resolution thermal infrared remote sensing and GIS to assess the urban heat island effect. Int. J. Remote Sens. 1997, 18, 287-304.

23. Sasidharan, N.V.; Rao, P.G.; Al-Mulla, A.H. A study of urban heat island intensity: the case of Doha. In Green CITYnomics: The Urban War against Climate Change; Tang, K., Ed. Greenleaf Publishing: Sheffield, UK, 2009.

24. Saaroni, H.; Ziv, B. Estimating the Urban Heat Island Contribution to Urban and Rural Air Temperature Differences over Complex Terrain: Application to an Arid City. J. Appl. Meteor. Climatol. 2010, 49, 2159-2166.

25. Comrie, A.C. Mapping a Wind-Modified Urban Heat Island in Tucson, Arizona (with Comments on Integrating Research and Undergraduate Learning). Bulletin of the American Meteorological Society 2000, 81, 2417-2431.

26. Roy, D.P.; Ju, J.; Mbow, C.; Frost, P.; Loveland, T. Accessing free Landsat data via the Internet: Africa's challenge. Remote Sens. Lett. 2010, 1, 111-117.

27. Population Division, Department of Economic and Social Affairs, United Nations. World Urbanization Prospects, the 2010 Revision; New York, 2010. 
SUPPLEMENTARY MATERIAL

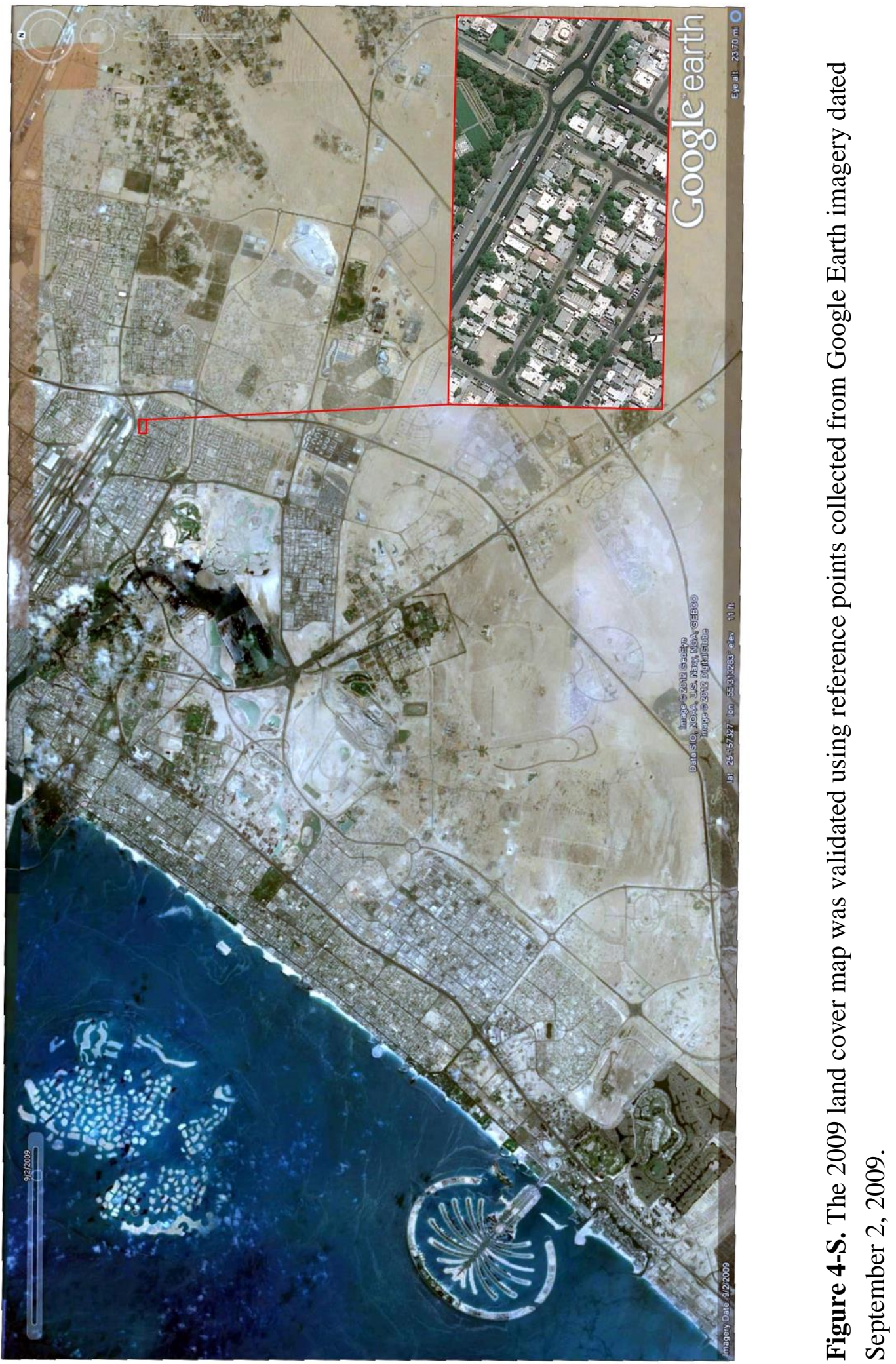


Figure 5-S. A segment of the study area before (A) and after (B) implementing the fill procedure. The SLC-off gaps were not wide enough to introduce significant error into the interpolation.

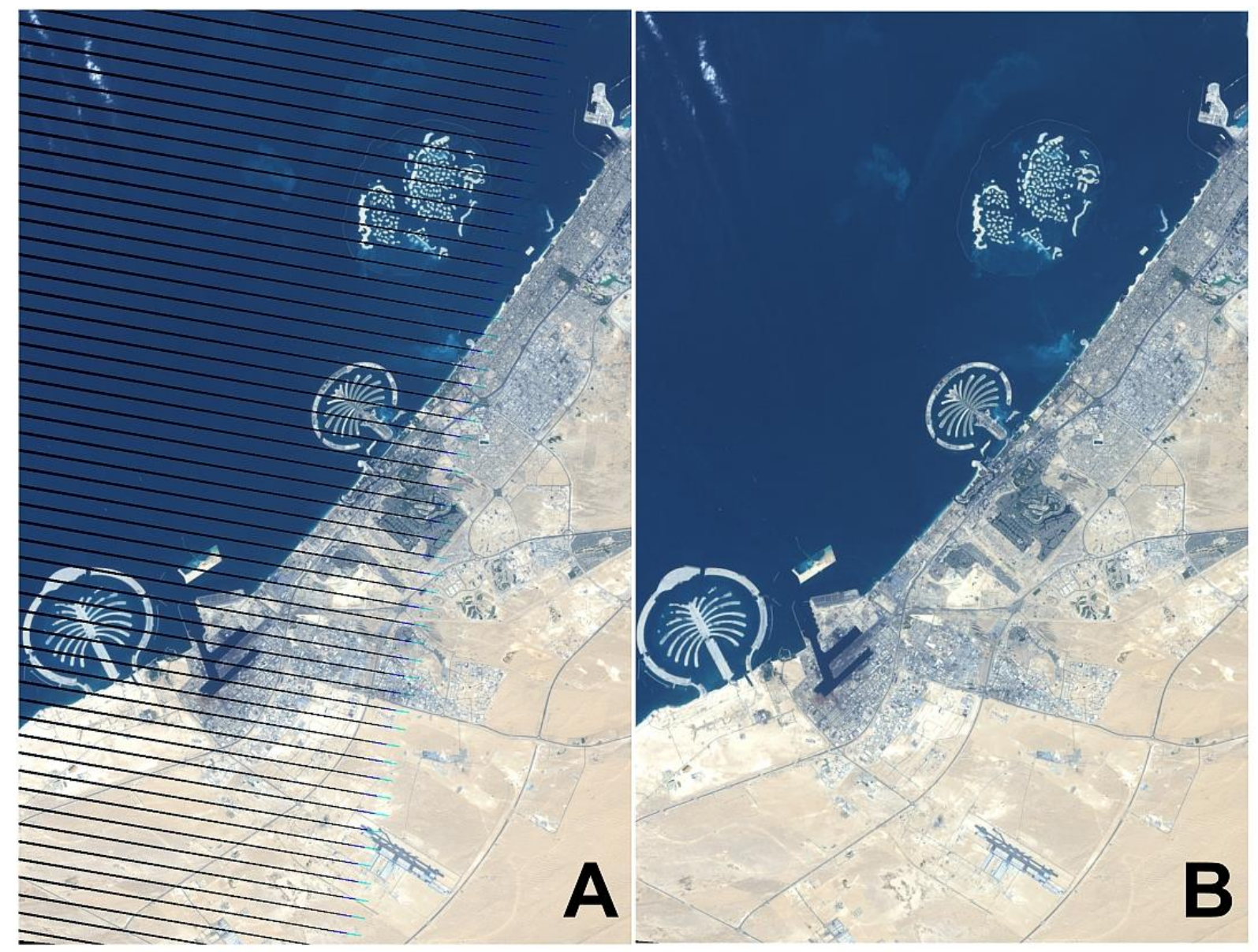

